\begin{tabular}{|c|c|c|c|c|c|c|c|}
\hline & & $\begin{array}{l}\text { Uncomplicated extraction } \\
(\%)\end{array}$ & $\begin{array}{l}\text { Major AE due to procedure } \\
(\%)\end{array}$ & $\begin{array}{l}\text { Major AE not due to } \\
\text { procedure (\%) }\end{array}$ & $\begin{array}{l}\text { Minor AE } \\
(\%)\end{array}$ & $\begin{array}{l}\text { Procedural failure } \\
(\%)\end{array}$ & $\begin{array}{l}>4 \mathrm{~cm} \text { lead remaining } \\
(\%)\end{array}$ \\
\hline \multirow[t]{5}{*}{$\begin{array}{l}\text { Reason } \\
\text { extracted }\end{array}$} & $\begin{array}{l}\text { Pocket } \\
\text { infection }\end{array}$ & $59(87)$ & $0(0)$ & $0(0)$ & $9(13)$ & $2(3)$ & $2(3)$ \\
\hline & Box erosion & $43(86)$ & $3(6)$ & $0(0)$ & $4(8)$ & 1 (2) & $0(0)$ \\
\hline & $\begin{array}{l}\text { Systemic } \\
\text { infection }\end{array}$ & $36(69)^{\mathrm{a}}$ & $0(0)$ & $6(12)^{a}$ & $10(19)^{a}$ & $5(24)^{c}$ & $0(0)$ \\
\hline & Lead failure & $72(90)$ & $2(3)$ & $0(0)$ & $6(8)$ & $4(2)$ & $4(2)$ \\
\hline & Other & 17 (94) & $0(0)$ & $0(0)$ & 1 (6) & $0(0)$ & $0(0)$ \\
\hline \multirow[t]{4}{*}{ Technique } & Simple traction & $97(92)$ & $3(3)$ & $2(2)$ & $3(3)$ & $2(2)$ & $1(1)$ \\
\hline & $\begin{array}{l}\text { Assisted } \\
\text { traction }\end{array}$ & $26(70)^{b}$ & $0(0)$ & $1(3)$ & $10(27)^{b}$ & $3(8)$ & $2(5)$ \\
\hline & Cutting sheath & $91(91)$ & $0(0)$ & $3(3)$ & 7 (7) & $7(7)$ & $3(3)$ \\
\hline & Laser & $18(72)^{b}$ & $2(8) \mathrm{b}$ & $0(0)$ & $5(20)^{b}$ & $0(0)$ & $0(0)$ \\
\hline
\end{tabular}

sheaths (5\%), bidirectional cutting sheaths (38\%) or laser (10\%). Only $2 \%$ of cases required additional femoral access. Specialist equipment was preferentially used for older leads $(10.4 \pm 13.1$ vs $5.2 \pm 5.8$ years, $\mathrm{p}<0.001)$ and for ICD leads (84\% vs 53\%, p<0.001).

The rate of major procedural adverse events (AE) leading to death or emergent surgery was $2.2 \%$, major AEs unrelated to the procedure was $5.8 \%$ and minor AEs was $8.7 \%$. Predictors of AEs include patient age $(77 \pm 28$ vs $66 \pm 15$ years, $\mathrm{p}=0.05)$, the age but not type or number of lead $(14.8$ \pm 24.5 vs $7.2 \pm 6.0$ years, $p=0.01)$, systemic infection ${ }^{\mathrm{a}}(31$ vs $8 \%, \mathrm{p}<0.001)$, increased creatinine level $(142 \pm 111$ vs 108 $\pm 23 \mu \mathrm{mol} / \mathrm{L}, \mathrm{p}=0.011)$, decreased haemoglobin level (109 \pm 23 vs $123 \pm 24 \mathrm{~g} / \mathrm{L}, \mathrm{p}=0.001)$ and use of assisted traction or laser over simple traction or mechanical cutting sheaths ${ }^{\mathrm{b}}$ $(\mathrm{p}=0.001)$ - see Table. Complete extraction was achieved in $95.5 \%$ of leads, with only $2.2 \%$ with $>4 \mathrm{~cm}$ of lead remaining in situ. Predictors of procedural failure include age but not type or number of leads $(11.1 \pm 8.6$ vs $8.3 \pm 11.3$ years, $\mathrm{p}=0.05)$, systemic infection ${ }^{\mathrm{c}}(24$ vs $3 \%, \mathrm{p}<0.001)$ and increased creatinine $(162 \pm 126$ vs $108 \pm 66 \mu \mathrm{mol} / \mathrm{L}, \mathrm{p}=0.012)$. Laser extraction resulted in $100 \%$ success in removing leads. Gender, procedure duration, fluoroscopy time and dose, use of general anaesthesia or temporary pacing was independent of extraction technique and outcome.

Discussion This is the first UK prospective multi-centre study of lead extraction data comparing extraction techniques. Overall there is a low major complication and high success rate with the use of either simple traction or specialist equipment. From our findings, high risk cases can be identified pre-procedure to allow adequate case planning. Laser extraction is clinically effective but is associated with a higher complication rates compared with mechanical cutting sheaths.

\section{FIVE YEARS ON - FAILURE TO APPLY 2010 NICE SYNCOPE GUIDELINES IN A LONDON TERTIARY CENTRE}

Nikhil Ahluwalia*, Conn Sugihara, Nicholas Gall. King's College Hospital

10.1136/heartjnl-2017-311726.36

Introduction NICE have recommended clear pathways for assessment of patients with transient loss of consciousness
(TLoC), with the aim of reducing unnecessary investigations, the length of hospital admission and aiming for early specialist assessment and better patient outcomes.

Methods A retrospective analysis of electronic case records for all patients referred by $\mathrm{A}$ and $\mathrm{E}$ for medical assessment in King's College Hospital in July and August 2015 was performed in August 2016. To capture all potential patients, any referral including the words fall, collapse, seizure, syncope, LoC, cardiac arrest or blackout were screened. Patients who did not have TLoC were excluded based on prespecified criteria. The remaining patient records were evaluated against the 2010 NICE guideline audit tool.

Results 2101 patients were referred over 2 months. 192 (9\%) were possible TLoC on the basis of the initial referral. After medical assessment, 147 patients were found not to have TLoC. The most common reasons were absence of LoC (75 pts), epileptic seizure with known epilepsy (24 pts) and drug or alcohol intoxication (17 pts). After screening, there were 45 patients $(2 \%$,$) with potential TLoC.$

No patient with TLoC had the all the NICE-mandated minimum data recorded. Unrecorded data included high risk features that should be the basis for TLoC admissions; family history of premature death (40\%), collapse during exertion (20\%), new or unexplained dyspnoea (18\%).

Although $82 \%$ had a CXR and $76 \%$ received CT head, $84 \%$ had no recorded postural BP and $24 \%$ had no record of an ECG. Only $16 \%$ were referred for inpatient evaluation by a cardiologist.

The mean length of stay was 7 days, equivalent to 5 bedyears on an annualised basis. However, 20\% were discharged without a diagnosis, and $36 \%$ did not have any outpatient follow up.

Conclusions Despite clear guidelines, syncope patients still do not receive appropriate initial evaluation, investigation or diagnosis, even in a large tertiary centre with ready access to specialist assessment. Hospital length of stay is long, yet simple diagnostic tests (such as ECGs and postural BPs) are commonly not performed.

Screening of all medical referrals based on simple criteria results in a relatively small number of patients with TLoC. Early specialist involvement in patients with syncope would be practically feasible, and would potentially result in better patient outcomes. 